\title{
Study on Mass Customization for Knowledge Production and its Operation Mode
}

\author{
Cuixiao FU ${ }^{1}$, Xingsan QIAN ${ }^{2}$ \\ ${ }^{1}$ School of Management, Fudan University, Shanghai, China \\ ${ }^{2}$ School of management, University of shanghai for science and technology, Shanghai, China
}

\begin{abstract}
With the development of network technology and the theory of mass customization for manufacturing, the knowledge production industry was impacted. On the driving of modern knowledge production characteristics and the drawing of the environment demand, a new knowledge production mode - the mass customization for knowledge production, was put forward. Based on the previous studies, the background and the concept model of knowledge production mode based on mass customization are introduced firstly; then, its operation processes are analyzed on spatial and time dimensions separately; finally, some issues are pointed out about the actualize of knowledge production based on mass customization.
\end{abstract}

Keywords: knowledge production, mass customization, operation mode

\section{1 引言}

近年來, 知識經濟大力發展, 促使了知識生產業 的繁榮。而知識生產的管理過程比較複雜, 一直以來, 各個知識生產企業 (將知識產品作為商品來生產的企 業)、團體或個人均是以自主的生產方式，在不斷探索 的過程中尋找適合自身的生產方式。面對製造業大規 模定制生產模式的蓬勃發展及成功實施, 知識生產企 業也必定受到一定衝擊, 把這種低成本, 高效率的生 產方式引入知識生產中，對知識生產將具有革命性的 意義。筆者已初步提出了面向知識生產的大規模定制 思想[1-3]，在此基礎上，本文對這種基於大規模定制 的知識生產模式 (Mass Customization for Knowledge Production, MCKP) 進一步展開深入研究。首先介紹 其提出背景及概念模型, 然後從空間和時間兩個維度 對其運作模式進行系統分析, 最後指出實施 MCKP 需 注意的幾個關健問題。

\section{MCKP 的概念模式}

\subsection{MCKP 的提出}

大規模定制 (MC) 是為適應激烈的市場競爭環 境而發展起來的, 根據用戶的個性化需求而提供定制 產品的一種生產模式, 它把定制和大規模生產這兩種 似乎矛盾的方式結合在一起, 實現以大規模、低成本的 方式生產個性化的產品, 為產品的低價格和多樣性找
到了一個平衡點[4-7]。已有許多研究者研究證明採用 模組化是實現大規模定制生產模式的要點[8,9]。

知識生產的特性及知識產品市場的環境條件均促 進了 MCKP 的提出。主要體現在以下幾個方面:

1) 知識的虛擬性, 知識生產可以在不同地域以不 同的方式進行，並可通過網路進行傳遞，擺脫了機械 製造業生產的運輸問題，大大增強了生產的靈活性， 使其較適於大規模定制的生產;

2) 而知識生產的非自然資源依賴性決定了其生 產者是具有智慧的素質型人才[9], 他們能在不斷發展 的生產活動中, 快速適應變化節奏, 領悟新觀念, 掌 握新技術，因此有利於其向大規模定制模式轉化;

3) 現代知識生產除依賴于人們的智慧以外, 主要 則依賴于現代資訊技術，資料存儲和轉換技術，各種 網路技術及其它知識技術等, 這些先進技術為實現 MCKP 提供了有利基礎;

4) 知識生產過程的複雜性及產品類型的多樣 性, 要實現快速生產, 就有必要採用大規模定制性模 式;

5) 知識經濟社會條件下, 人們對知識產品的需求 增大，個性化程度增強，而同時，知識生產企業的急 速增多使市場競爭日趨激烈，在這種市場環境下，只 有實施大規模定制的生產模式才能提升企業競爭力, 更好地滿足消費者需求。

可見, MCKP 是為適應現代網路技術的發展, 由 自身特點推動，及外部市場環境拉動的共同作用下而 
提出的一種高效的知識生產模式。

\subsection{MCKP 的概念模型[2]}

MCKP 的基本思想即是在 MC 理論的指導下，利 用相似性原理把單個客戶的個性化需求轉化為大量客 戶的共同需求，以實現大規模生產；另一方面根據知 識產品特徵劃分出不同的生產模組，利用網路優勢， 充分調動分佈於不同地域的協作組織或個體知識生產 者進行模組化生產, 同時利用知識可無限重用的特 性，在模組內盡可能實施標準化生產，以提高生產效 率; 最終通過網路進行整合產品, 而實現以大規模生 產的成本和速度，為顧客提供多樣化、個性化的產品。

MCKP 的概念模型如圖 1 所示。首先客戶的個性
化需求資訊經由網路平臺傳遞給知識生產企業; 然後 企業根據需求資訊，利用相似性原理將需求聚類，再 利用先進知識技術進行知識模組化設計, 此時需求資 訊轉化為模組化設計資訊; 隨後, 模組化設計資訊進 一步轉化為生產調度資訊, 即按著模組化設計要求, 企業進行合理的生產調度, 以安排生產, 此時生產調 度資訊的傳遞過程是由知識生產企業到協作生產組織 再到個體生產者。其中模組化及生產調度過程中均與 人力資源管理及知識管理發生資訊交換關係。這是由 於知識生產中最主要的資源即是人力資源及其知識資 源, 其人力資源管理與知識管理是知識生產的關鍵, 因此 MCKP 的實現也與其人力資源管理及知識管理 密切相關。

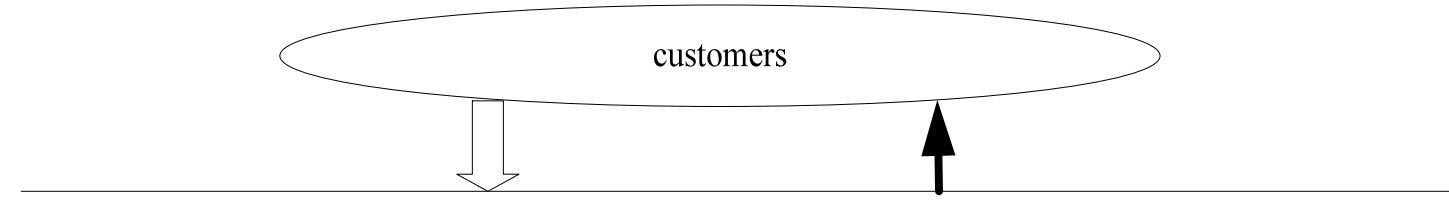

Network platform

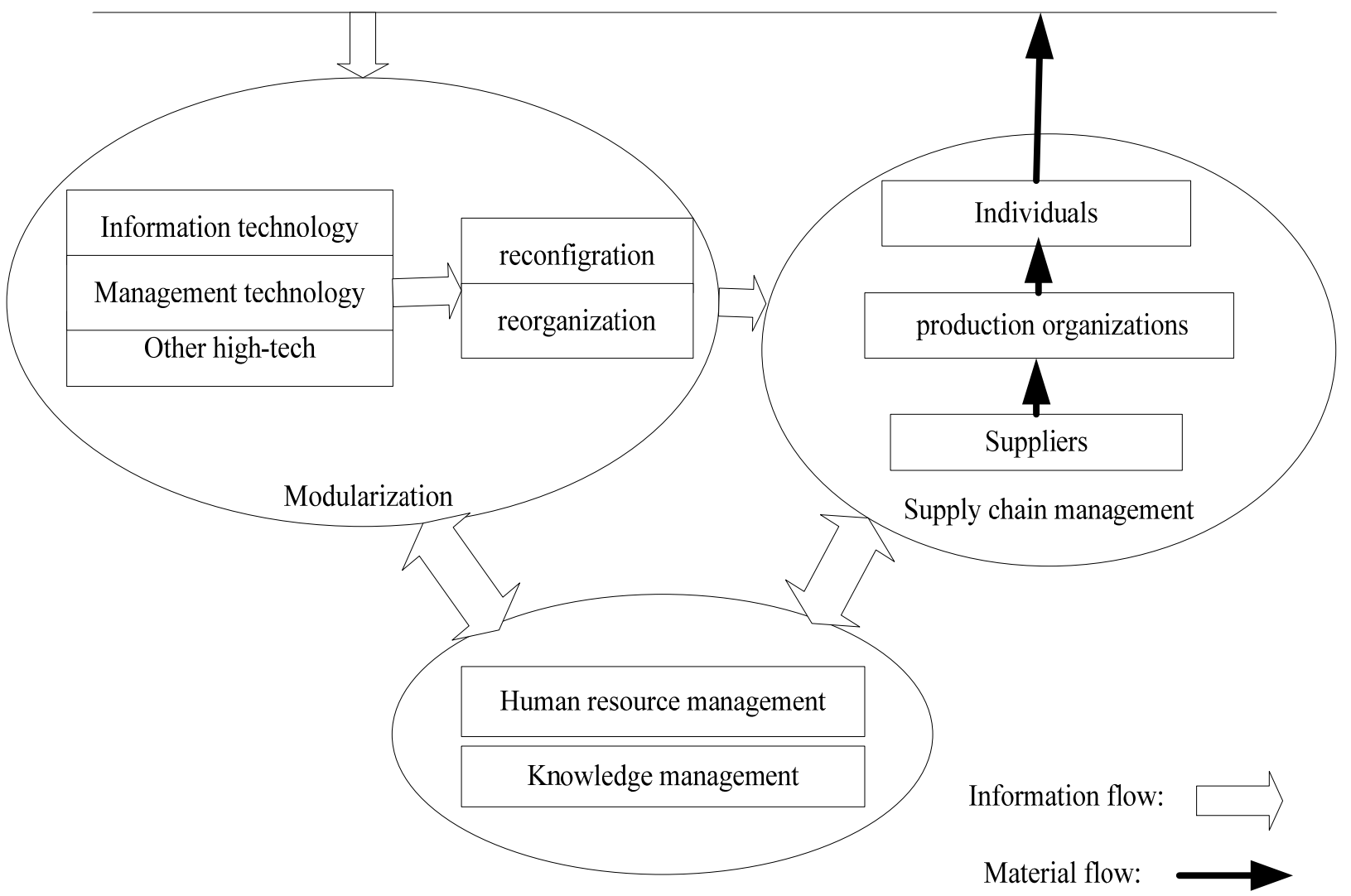

圖1. MCKP的概念模型

Figure 1. The conceptual model of MCKP 


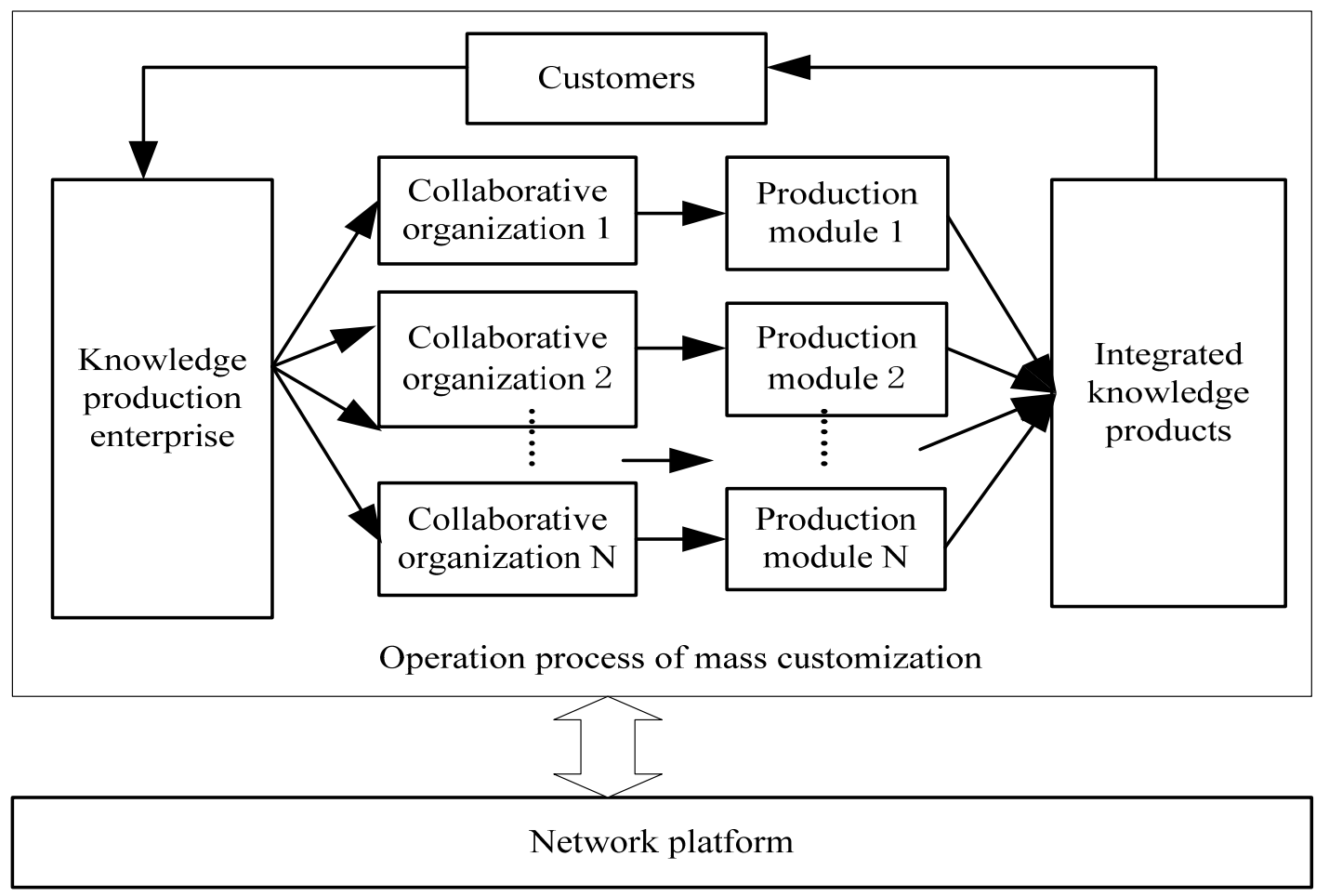

圖 2. MCKP 的空間動作模式

Figure 2. The spatial operation mode of MCKP

MCKP 中的物質流主要指知識生產過程中, 知識 產品的傳遞過程, 即首先從單個知識生產者生產出的 知識產品單元, 到協作生產組織, 經整合形成模組化 的知識產品模組, 再到知識生產企業, 進一步整合形 成個性化的知識產品, 最後交付客戶。

\section{MCKP 的空間運作模式}

MCKP 的運作模式可從空間和時間兩個角度來探 討, 空間角度, 即是站在生產者, 產品和客戶的關係 層面考慮 MCKP 的運作, 而忽略具體的生產階段的劃 分; 而時間角度, 則重點考慮按時間順序所進行的各 個生產階段, 即生產流程。

從空間角度來看, MCKP 的運作模式如圖 2 所示 [3], 可描述為: 知識生產企業充分利用網路優勢, 將 全球的具有個性化需求的客戶統一歸類, 即利用相似 性原理把單個客戶的個性化需求轉化為大量客戶的共 同需求, 以實現大規模生產; 另一方面根據產品特徵 劃分出不同的生產模組, 同樣利用網路優勢, 充分調 動分佈於不同地域的協作組織或個體知識生產者進行 模組化生產, 同時利用知識可無限重用的特性, 在模 組內盡可能實施標準化生產, 以提高生產效率; 然後,
將各模組的產品通過網路平臺進行整合, 並按客戶需 求進行複製等其他非創新生產活動, 最終交付客戶。 MCKP 的整個生產過程一直是在網路平臺的協助下進 行的。這種模式下, 知識的創新活動不再只是知識生 產企業內部員工的任務, 而是充分聯合了全球環境下 的相關協作組織共同進行, 從而在單個協作組織中形 成了規模化、標準化的生產, 而整合後的產品對於單 個客戶來講卻是個性化的。

\section{MCKP 的業務流程}

文獻[1]已初步對知識生產的大規模定制流程進行 了簡要描述, 基於此, 我們進一步對其業務流程進行 較為深入的研究。

當知識生產企業實施大規模定制模式時，在按客 戶訂單生產的同時也會根據市場預測, 通過需求分 析, 以知識重用為目的, 自主開發新產品, 這種創新 知識產品的生產流程如圖 3 所示 主要包括以下步驟:

1) 市場預測。對未來一定時期, 一定地域內, 可 能獲得的市場銷售預計值進行估計，提出可靠的預估 資料, 供決策人員參考, 進行市場預測是開始知識生 產的第一步，是整個生產系統的資料登錄的依據。 


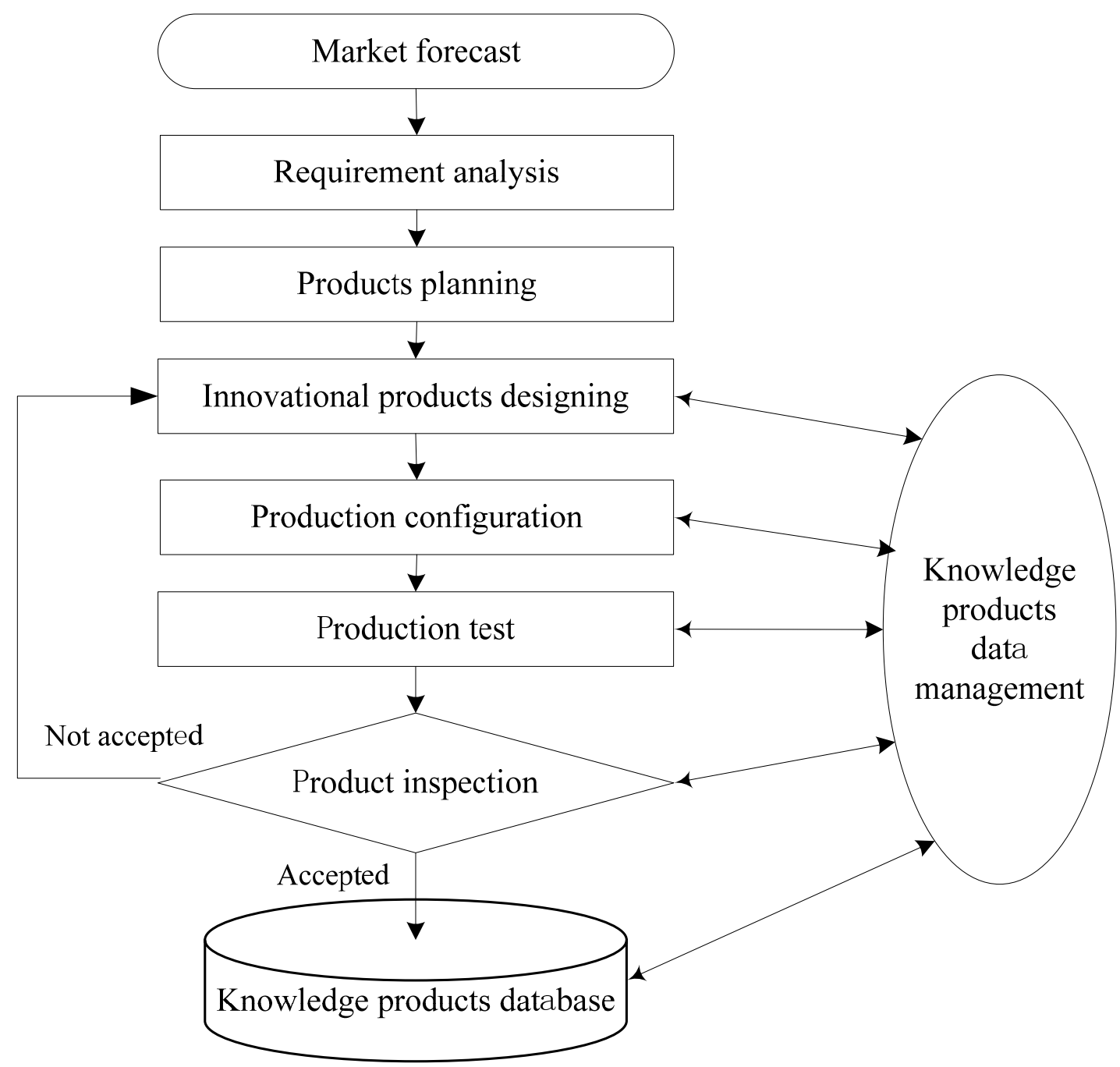

圖 3. 創新知識產品的生產流程

Figure 3. The operation flow of innovational knowledge products

2) 需求分析。根據預測資料, 對用戶需求進行分 析, 確定用戶需求類別及需求量, 分析影響各類知識 產品需求的因素及其重要性。

3) 產品規劃。根據預測及需求分析結果, 對知識 產品進行整體規劃, 即定義及表達知識產品在整個生 產全過程中所需的資訊, 確定最佳的產品模式、崖品 組合等。

4) 產品設計。對產品的生產方案進行詳細設計, 包括對其功能、結構、特點、模組化、生產流程、資 源配置等細節進行系統設計, 整個設計生產過程均需 在知識產品資料管理技術的支撑下進行。

5) 生產配置。根據產品的規劃及設計要求, 配置 生產所需的設備、人員、材料等資源。

6) 生產測試。按產品規劃及設計流程進行測試性
生產。

7) 產品檢驗。對測試生產出的產品進行檢驗, 若 產品合格則存入知識產品庫中, 過程結束。若產品不 合格, 則回到第(4)步, 重新進行設計生產。

訂單知識產品的生產流程如圖 4 所示, 其中既含 有創新生產, 也有複製生產的部分。其業務流程描述 如下:

1) 客戶訂單。客戶通過 MCKP 的網路平臺或其 他方式向企業表達其產品需求，下達訂單;

2) 訂單管理。企業在接到客戶訂單後, 對其進行 統一管理;

3) 產品模組化設計。根據訂單類別, 所需產品性 能特點對訂單產品進行模組化設計;

4) 主生產計畫。根據產品設計, 制定主生產計畫, 


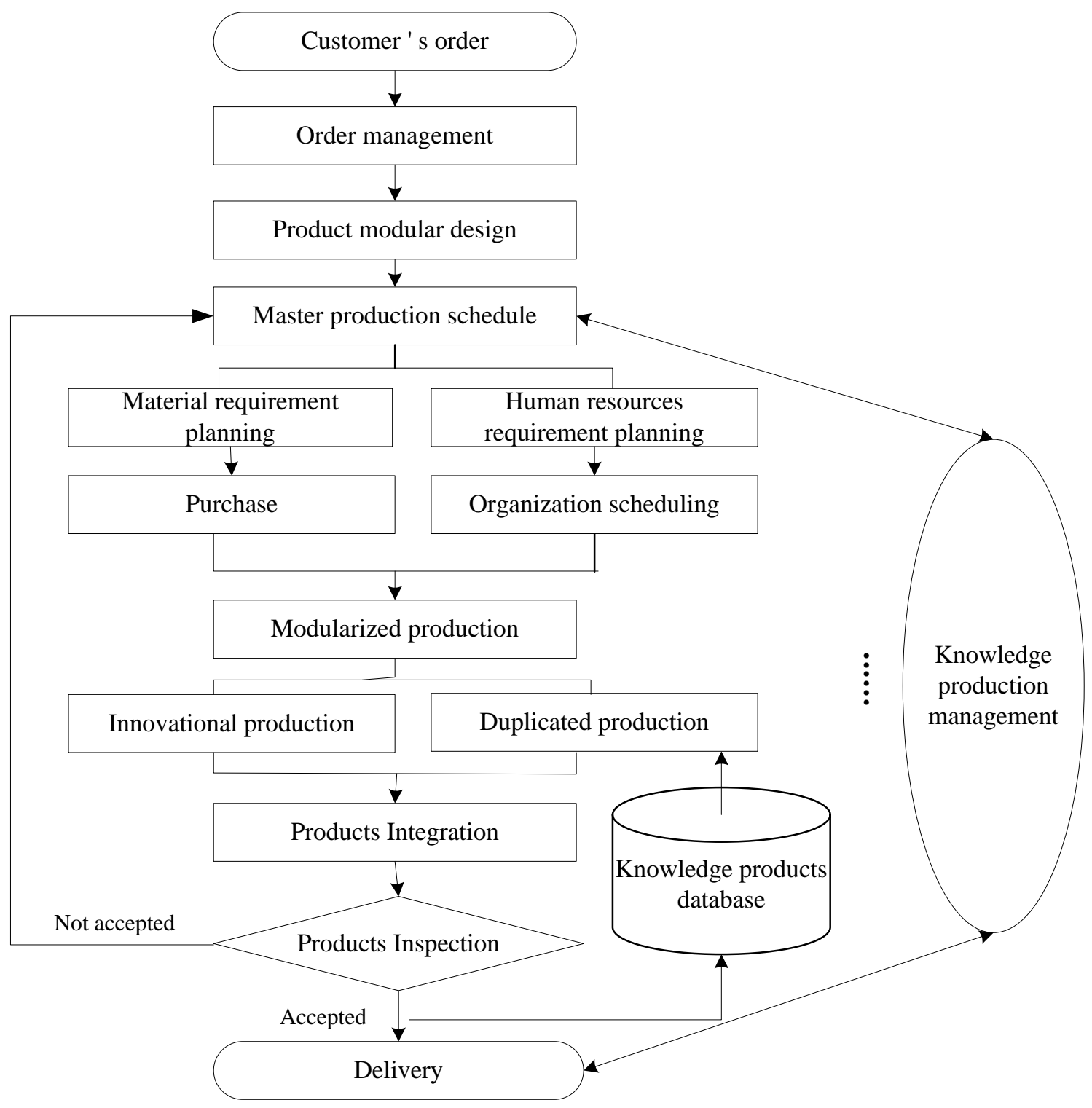

圖 4. 訂單知識產品的生產流程

Figure 4. The operation flow of customized knowledge products

包括物質資源需求計畫及人力資源需求計畫;

5) 資源配置。根據物質資源計畫對所需設備及資 料進行採購, 根據人力資源需求計畫進行組織調配;

6) 模組化生產。根據產品模組化設計及主生產計 畫, 進行知識產品的模組化生產, 生產過程中包括創 新生產和複製生產兩部分, 其中複製生產是由知識產 品庫中已存產品進行複製的過程;

7) 產品整合。將各個生產模組生產出的產品按不 同方式進行適當整合，形成產品簇及滿足客戶個性化 需求的知諳產品;

8) 產品檢驗, 由生產企業及客戶雙方對產品進行
檢驗, 產品合格則交付客戶, 同時存入知識產品資料 庫, 以備日後重用。若產品不合格, 則回到第(3)步, 重要對產品進行設計生產。

需要指出的是, 在整個定制產品的生產過程中, 知識生產管理是使知識生產的大規模定制得以有效運 行的重要保證。

\section{5 實施 MCKP 時需注意的問題}

知識生產的獨特性決定了其在實施大規模定 制過程中，不可能直接照搬製造業生產的大規模定 
制模式，而必須針對知識生產的特點，應用大規模 定制的基本理念，設計系統的管理模式，實施過程 中需重點注意以下幾個問題。

\section{1 知識產權問題}

知識產品的研發需耗費知識生產者的時間和 精力, 經過較複雜的過程方能完成, 而另一方面, 為增加知識應用的概率和範圍, 提高知識生產力, 就必需將知識公開披露。知識的公開, 使知識發現 的優先權保護成為必然。對於知識生產的大規模定 制來說, 其本身包含有複製生產的部分, 如何保護 原創知識生產者的利益無疑成為這種模式實施的 一個重要前提, 是知識生產企業實施大規模定制時 首先要考慮的問題。

\section{2 組織調度問題}

知識生產主體的多樣性使參與知識生產的組 織或個人難以形成一個穩定的組織結構, 在實施知 識生產的大規模定制過程中, 必將借助現代網路技 術, 通過網路平臺, 使很多虛擬的員工或協作單位 共同參與進知識生產活動。如何有效的組織和利用 這些無限的人力資源是知識生產企業需要重視的 問題。同時, 在客戶個性化的定制需求下, 如何選 擇合適的生產者使生產的效率及效益最高, 顯然是 企業最關注的問題, 因而做好企業的組織調度工 作，是實施大規模定制的關鍵。

\section{3 人力資源管理問題}

知識生產最主要的生產資源即是人力資源, 知 識生產的大規模定制實施, 將使更多的人參與進知 識生產中來, 不同素質層次, 不同專業, 地域或身 份的人共同構成知識生產企業的寶貴財富, 於是人 力資源管理顯然成為知識生產管理中最主要的內 容。但知識生產的人才評估不像物質生產那樣能簡 單計算出其投入產出, 人的知識具有動態, 虛擬及
不確定性，如何進行合理的評估，建立評估體系， 是知識生產企業實施大規模定制過程中的一個難 點, 也是知識生產企業成功實施這種模式的前提條 件之一。

\section{REFERENCES}

[1] Fu, C. X. and Qian, X. S., "Research on mass customization for knowledge production,” In The International Conference on Operations and Supply Chain Management, Xi'an, China, pp. 203-207, June 2007.

[2] Fu, C. X. and Qian, X. S., "Mass customization mode of knowledge production and its application method," Systems Engineering, No. 7, pp. 1-6, July 2008.

[3] Fu, C. X. and Qian, X. S., "Study on mass customization for knowledge production and its cost model," In Management Track within Wicom: Engineering, Services and Knowledge Management, EMS2008, Dalian, China, October 2008.

[4] Pine, B. J., "Mass customization: The new frontier in business competition,” Boston: Harvard Business School Press, 1993.

[5] Eastwood and Margaret, A., "Implementing mass customization,” Computers in Industry, No. 3, pp. 171-174.

[6] Beaty, R. T., "Mass customization,” Manufacturing Engineer, No. 5, pp. 217-220, 1996.

[7] Dan, B., et al., "Mass customization," Beijing: Science Press, 2004.

[8] Duray, R., "Mass customization origins: Mass or custom manufacturing,” International Journal of Operations and Productions Management, Vol. 22, No. 3, pp. 314-328, 2002.

[9] Kumar, A., "Mass customization: Metrics and modularity,” The International Journal of Flexible Manufacturing Systems, Vol. 16, pp. 287-311, 2004. 